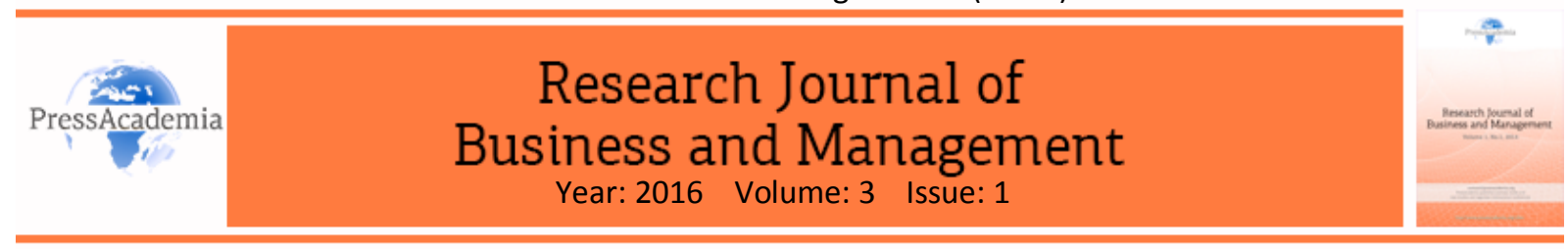

\title{
THE IMPACT OF TRANSFORMATIONAL LEADERSHIP ON MANAGEMENT INNOVATION: AN EMPIRICAL RESEARCH IN TURKEY
}

\section{DOI: 10.17261/Pressacademia.2016116548}

\author{
Faruk Kalay', Turgay Ozturk ${ }^{2}$ \\ 'Yuzuncu Yil University, Faculty of Business. kalayfaruk@hotmail.com \\ ${ }^{2}$ Kara Kuvvetleri Komutanlığı.turgayozturkkibris@gmail.com
}

\begin{abstract}
The number of academic researches on innovation has been steadily on the rise. Yet these researches focus primarily on economic impacts of technological transformations and product and process innovations based on technology (Damanpour, 2014). The number of researches and academic publications about management innovation are relatively low with respect to technological innovation. Yet organizational innovations occurred as a result of management innovations, are considered as a prerequisite for technological innovations (Sanidas, 2005). In this regard, the aim of this study is to analyze the impact of transformational leadership sub-components such as idealized influence (charisma), inspirational motivation, intellectual stimulation and individual consideration on management innovation. The research data are obtained through 198 Turkish public managers. The analyses reveals that individual consideration has a positive and significant impact on management innovation, whereas other sub-components such as idealized influence (charisma), inspirational motivation, intellectual stimulation do not cause a significant impact.
\end{abstract}

Keywords: Management innovation, innovation, transformational leadership, Leadership, administrative innovation. JEL Classification: M1, 030, 031

\section{DÖNÜŞÜMSEL LIDERLIK DAVRANIŞININ YÖNETIM INOVASYONU ÜZERINDEKI ETKISi: TÜRKIYE'DE AMPIRIK BIR ARAŞTIRMA}

\section{ÖZET}

İnovasyonla ilgili akademik araştırmaların sayısı her geçen gün artmaktadır. Ancak bu araştırmaların daha çok teknolojik değişimlerin ekonomik etkilerine ve teknoloji tabanlı ürün ve süreç inovasyonlarına odaklandığı görülmektedir (Damanpour, 2014). Yönetim inovasyonuyla ilgili araştırma ve akademik yayın sayısı, teknolojik inovasyona nazaran göreceli olarak daha azdır. Ancak, yönetim inovasyonlarının yapılması sonucu oluşacak organizasyonel değişimlerin, aslında çoğu zaman teknolojik inovasyonları yapmanın bir ön koşulu olduğu ifade edilmektedir (Sanidas, 2005). Bu bağlamda bu çalışmanın amacı, dönüşümsel liderlik davranışı alt boyutları olan idealleştirilmiş etki (karizma), ilham verme (telkinle güdüleme), entelektüel teşvik ve bireyselleştirilmiş ilgi liderlik davranışının yönetim inovasyonu üzerindeki etkisini araştırmaktır. Araştırma Türkiye'de bir kamu kurumunda çalışan 198 yöneticiden alınan verilerle gerçekleştirilmiştir. Analizler sonucunda bireyselleştirilmiş ilgi liderlik davranışının yönetim inovasyonu üzerinde pozitif ve anlamlı bir etkiye sahip olduğu tespit edilmiştir. Bununla birlikte diğer boyutlar olan idealleştirilmiş etki (karizma), ilham verme (telkinle güdüleme) ve entelektüel teşvik liderlik davranışlarının yönetim inovasyonu üzerinde anlamlı bir etkiye sahip olmadıkları tespit edilmiştir.

Anahtar Kelimeler: Yönetim inovasyonu, inovasyon, dönüşümcü liderlik, liderlik, idari inovasyon.

JEL Sınıflandırması: M1, O30, O31 


\author{
“...Atatürk'te aslında çok yönler vardır. Atatürk'te olan, her zaman kolay bulunmayan ve her liderde \\ görülmeyen bir yön daha vardır. Atatürk, her zaman akılcı, ileriye dönük, gelişmeden yana, demokratik \\ düzenden yana bir lider olmuştur" (Mendes, 1981).
}

\title{
1. GiRiş
}

Birçok akademik disiplinde popüler bir araştırma alanı olan inovasyon, yeni endüstriler yaratmak, ekonomik büyüme sağlamak, rekabet avantajı elde etmek, firma performansını artırmak ve hem özel sektör işletmelerini hem de kamu sektörü kurumlarını etkili yönetebilmek için temel bir kavram olarak değerlendirilmektedir. Dolayısıyla inovasyonla ilgili akademik araştırmaların sayısı her geçen gün artmaktadır. Ancak bu araştırmaların daha çok teknolojik değişimlerin ekonomik etkilerine ve teknoloji tabanlı ürün ve süreç inovasyonlarına odaklandığı görülmektedir (Armbruster vd., 2008; Birkinshaw vd., 2008; Vaccaro vd., 2012; Damanpour, 2014). Başka bir ifadeyle yönetim inovasyonuyla ilgili araştırma ve akademik yayın sayısı, teknolojik inovasyona nazaran göreceli olarak daha azdır (Vaccaro vd., 2012).

İnovasyon literatürüyle ilgili bu istatistiki bilgiler, aslında inovasyonun öncelikle teknoloji tabanlı bir olgu olarak kavramsallaştııılığını göstermektedir. Ancak, hem ekonomi hem de organizasyonel araştırmacılar, inovasyonun aslında sadece teknolojik bir olgu olarak alınmaması gerektiğini, inovasyonun aynı zamanda teknolojik alanın ötesinde bir olgu olduğunu ifade etmektedirler (Damanpour, 2014; Vaccaro vd., 2012). Rekabet koşulları, teknolojik değişimler ve çevresel değişimler, işletmelere sadece yeni ürün ve hizmetler yaratmanın ötesinde aynı zamanda işletmelerde yönetimin doğasını da değiştirmeyi dayatmaktadır. Dolayısıyla rekabet avantajı gibi son derece değerli bir kaynağa sahip olmak için örgüt yapısında, süreçlerde ve yönetim pratiklerinde yönetim inovasyonları yapmak son derece önemlidir. Arrow (1962), Nelson (1991) ve Sanidas (2005), yönetim inovasyonlarının yapılması sonucu oluşacak organizasyonel değişimlerin, aslında çoğu zaman teknolojik inovasyonları yapmanın bir ön koşulu olduğunu ifade etmektedirler. Benzer şekilde organizasyon alanıyla ilgili araştırmacılar, organizasyonların sürdürülebilir bir performans ve büyüme yakalamaları için stratejilerini, yapılarını ve süreçlerini değiştirecek yeni yönetim pratikleri üretmeleri gerektiğini ifade etmektedirler (Armbruster vd., 2008; Birkinshaw vd., 2008; Damanpour ve Aravind, 2012; Damanpour, 2014).

Birkinshaw vd. (2008) yönetim inovasyonunu; organizasyonel amaçları gerçekleştirme niyetiyle yönetim sanatı için yeni olan bir yönetim pratiği, süreci veya tekniğinin üretilmesi ve uygulanması olarak tanımlamaktadırlar (s. 829). En iyi bilinen yönetim inovasyonu örnekleri; Toyota tarafından gerçekleştirilen yalın üretim (lean production) ile Procter \& Gamble tarafından geliştirilen marka yönetimi örnekleridir (Vaccaro vd., 2012). Johnson'a (2010) göre ise, 15. yüzyılda ortaya çıkarılan "çift-kayıt muhasebe sistemi (double-entry accounting)", en önemli yönetim inovasyonu olarak değerlendirilebilir. Araştırmacılar, liderlik davranışlarının organizasyonlarda inovatif düşünceyi ve organizasyonel seçimleri etkilediğini ifade etmişlerdir (örn., Zhou ve George, 2003; Vaccaro vd., 2012). Bu bağlamda bu çalışmanın amacı, dönüşümsel liderlik davranışı alt boyutları olan karizma (idealleştirilmiş etki) liderlik davranışı, ilham verme (telkinle güdüleme) liderlik davranışı, entelektüel teşvik liderlik davranışı ve bireyselleştirilmiş ilgi liderlik davranışının yönetim inovasyonu üzerindeki etkisini araştırmaktır. Genel itibariyle yönetim inovasyonuyla ilgili ve daha spesifik olarak dönüşümsel liderlik davranışlarının yönetim inovasyonu üzerindeki etkisiyle ilgili araştırma sayısının çok kısıtı olması, bu çalışmayı önemli kılmaktadır. Çalışma, yönetimsel ve sektörel bir bakış açısıyla dönüşümsel liderlik davranışlarının yönetim inovasyonunu nasıl etkilediğini anlama konusunda önemli bulgular sunmaktadır. Çalışma aynı zamanda yönetim inovasyonu ve dönüşümsel liderlik ilişkisiyle ilgili olarak mevcut kısıtlı literatüre önemli ampirik bulgular sunmaktadır.

\section{TEORI VE HIPOTEZLER}

\subsection{Yönetim İnovasyonu}

Bugün yönetim inovasyonunun temellerini oluşturan yeni yönetim teknikleri ve pratikleri konusu, aslında yönetim inovasyonu kavramı ortaya atılmadan çok önceleri de gündemde olan konulardı. Bununla birlikte inovasyonun çağdaş kavramsallaştııılması ve inovasyonun tipolojileri 20. yüzyııın başlarında Schumpeter (1911; İngilizce baskı, 1934) tarafından yapılmışır. Schumpeter (1934), inovasyonu, yeni kombinasyonlarla üretilen 
yeni çıktılar olarak tanımlamakta ve inovasyonu; 1) yeni ürünler (“yeni bir ürünün üretilmesi ... veya var olan bir ürünün yeni bir kalitede üretilmesi”), 2) yeni üretim teknikleri, 3) yeni pazarlar, 4) yeni tedarik kaynakları ve 5) işletmeleri organize etmenin yeni yolları olmak üzere beş tipolojiye ayırmaktadır (Schumpeter, 1934, s. 66). Schumpeter, bu tipolojileri ekonomik gelişme ve teknolojik değişim bağlamında üretmiştir (Damanpour, 2014). Dolayısıyla söz konusu tipolojiler, organizasyon sisteminden çok ekonomik sisteme, hizmet organizasyonlarından çok imalat organizasyonlarına, teknolojik olmayan inovasyonlardan çok teknolojik inovasyonlara uygulanabilirler. Yönetim inovasyonu organizasyonel düzeyde bir olgudur ve Schumpeter'in inovasyon tanımı ve sınıflandırmasından sonra ortaya çıkmış bir kavramdır. Schumpeter, inovasyonun ekonomik gelişme üzerindeki rolüyle ilgili olarak iki perspektif sunmaktadır (Sanidas, 2005). illk çalışmasında, Schumpeter Mark I olarak da adlandırılan "inovasyon girişimcilik modelini (entrepreneurial model of innovation)" savunmaktadır. Bu model, öncelikle yeni endüstriler (ölçek ekonomileri) ve ürün sınıfları üreterek ekonomik büyümeye katkı sağlayacak start-up işletmelere odaklanmıştır. Daha sonra, büyük ölçekli ve kurumsal işletmelerin ekonomik büyüme ve inovasyon yaratmadaki öncelikli rolüne odaklanan Schumpeter Mark II olarak da adlandırılan "inovasyon kurumsal modelini (corporate model of innovation) geliştirmiştir (Schumpeter, 1942). Sanidas (2005), girişimcilik ve kurumsal modellerini sırasıyla "yaratıcı yıkım" ve "yaratıcı birikim" modelleri olarak ele almıştır.

Yönetim inovasyonunun teknolojik inovasyondan farkını tanımlamak açısından inovasyon girişimcilik modeli ve inovasyon kurumsal modeli arasındaki fark önemlidir. Zira küçük start-up işletmeler için yönetim inovasyonları ürün veya süreç inovasyonları kadar önemli olmayabilir. Diğer taraftan, orta veya büyük ölçekli bir işletmede aktivitelerin ve fonksiyonların karmaşıklığı ve büyüklüğü, operasyonların ve sistemlerin etkinlik ve etkililiğini artırmak ve stratejik dönüşüme imkan sağlamak için yeni yönetim pratikleri ve teknikleri üretmek gerekebilir. Araştırma sonuçları, yönetim inovasyonunun küçük işletmelere nazaran daha çok büyük işletmelerle ilgili olduğunu ve dolayısıyla inovasyon girişimcilik modelinden ziyade inovasyon kurumsal modeliyle ilişkili olduğunu göstermektedir (Chandy ve Tellis, 2000).

Yönetim inovasyonu (management innovation); aynı zamanda idari (administrative) inovasyon, yönetimsel (managerial) inovasyon, organizasyonel (organizationel) inovasyon ve sosyal (social) inovasyon gibi birbiriyle örtüşen birçok kavramla ifade edilen bir inovasyon tipidir (Damanpour, 2014). Bu terimler arasındaki ortak nokta, bu inovasyon tiplerinin teknolojik inovasyondan farklı olduğu hususudur. Yönetim inovasyonu kavramının bu kadar farklı disiplinel bakış açısıyla farklı terimlerle kavramsallaştırılması, kavramın anlaşıımasını ve gelişimini engellemektedir. Damanpour (2014), birbirlerinden farklı kavramsallaştırmaların önceliklerinden yola çıkarak, yeni bir yönetim inovasyonu tanımının yapılması gerektiğine işaret etmektedir. Damanpur'a (2014) göre, teknolojik inovasyonun ürün ve süreç inovasyonu olmak üzere iki gruba ayrıldığı hususunda konsensüs sağlandığı gibi, yönetim inovasyonu tipleri üzerinde de konsensüs sağlamak yönetim inovasyonu kavramıyla ilgili belirsizliği düşürecek ve konuyla ilgili araştırmaları kolaylaştıracaktır.

Yönetimsel inovasyon (managerial innovation) terimini ortaya atan Kimberly (1981), terimin tanımını "yöneticilerin ne olduğu ve ne yaptığıyla" ilişkilendirmiştir. Yöneticileri karar vericiler olarak değerlendiren Kimberly (1981), yönetimsel inovasyonunu ise karar verme süreçlerindeki değişim olarak ele almıştır. Söz konusu yazar, yönetim inovasyonunu, "karar verme süreçlerinde kullanılan bilginin doğasını, kullanım yerini, kalitesini ve niceliğini etkileyen, mevcut durumda var olan yönetim sanatından anlamlı bir şekilde farklı yeni bir program, ürün veya teknik" olarak tanımlamaktadır (Kimberly, 1981, s. 86).

Yönetimsel inovasyondan daha yeni bir terim olan yönetim inovasyonu "yöneticilerin ne yaptığı ve nasıl yaptığıyla" ilişkilendirilmiştir (Hamel, 2006). Yönetim inovasyonu, yönetim işinin yapılış yolunu, yöneticilerin ne yaptığını ve nasıl yaptığını ve organizasyon içinde işlerin yapılış kural ve yordamlarını değiştirmek için geleneksel yönetim ilkeleri, süreçleri ve pratiklerinden uzaklaşmak olarak tanımlanmaktadır (Birkinshaw vd., 2008; Hamel, 2006). Yönetim inovasyonları, yöneticilerin ve organizasyon üyelerinin çalışmasını değiştirecek strateji, yapı ve süreçler oluşturmaya yönelik yeni yaklaşımlardır (Vaccaro vd., 2012; Walker vd., 2011). Birkinshaw vd. (2008), inovasyonun odaklandığı hususları da göz önünde bulundurarak, yönetim inovasyonunu, yönetim sanatının mevcut durumundan farklı yeni bir şey olarak tanımlamaktadırlar. OECD (2005) Oslo kılavuzunda yönetim inovasyonu; firmaların ticari uygulamalarında, dışarıyla olan ilişkilerinde veya iş yeri organizasyonunda yeni organizasyonel yöntemleri uygulaması şeklinde tanımlanmaktadır (s. 55). Genel olarak ürün, hizmet ve 
teknolojik süreç inovasyonlarından farkı bağlamında kavramsallaştırılan yönetim inovasyonu terimi, bu çalışmada, organizasyonun yönetimsel prosedürlerinde ve idari sistemlerinde değişimlere neden olacak yönetim işinin yapılmasıyla ilgili yeni bir yaklaşım, yeni bir organizasyonel strateji ve yapı veya yeni süreçler geliştirmek ve kullanmak olarak tanımlanmaktadır (Birkinshaw vd., 2008; Damanpour ve Aravind, 2012; Vaccaro vd., 2012).

Yönetim inovasyonu tipleri: Araştırmacılar yönetim inovasyonu çeşitlerini farklı şekillerde sınıflandırmışlardır. Örneğin Whittington vd. (1999), yönetim inovasyonunu yapı, süreç ve sınırlar olmak üzere üç gruba ayırmışlardır. Damanpour (2014), stratejik ve yapısal inovasyonlar olarak ayırmıştır. Walker vd. (2011) ise, bilişim teknolojileri tabanlı ve idari tabanlı yönetim inovasyonu olmak üzere iki gruba ayırmışlardır. Organizasyonlar arası bağlamda bir süreç perspektifini benimseyen araştırmacılar ise amaçlarda, çalışanları motive etmede, aktiviteleri koordine etmede, kaynak dağılımında kullanılan karar süreçlerinde yapılan inovasyonlar olarak sınıflandırmışlardır. Armbruster vd. (2008), örgütsel yapıda (merkezileşme, çapraz fonksiyonel takımlar), organizasyonlar arası yapısal ilişkilerde (ittifaklar, dış kaynaklardan yararlanma), organizasyon içindeki prosedürlerde (iş zenginleştirme, kalite çemberleri) ve organizasyonlar arası prosedürlerde (tedarik zinciri yönetimi, müşterilerle tam zamanlı etkileşim) yapılan yönetim inovasyonları olmak üzere dört alt gruba ayırmışlardır. Battisti ve Stoneman (2010), yönetim inovasyonunu strateji, organizasyon (yapı) ve yönetim (süreç) inovasyonu olarak ayırmıştır. Son zamanlarda OECD (2005) Oslo kılavuzu (Oslo manual) ve topluluk inovasyon araştırması (CIS), yönetim inovasyonu tipleri için çeşitli standartlar önermektedir. Türkiye'de de Türkiye İstatistik Kurumu tarafından inovasyon anketi olarak uygulanan CIS (2012, s. 8), üç tip yönetim inovasyonuyla ilgili verileri toplamak için gerekli soruları içermektedir. CIS (2012, s. 8)'deki yönetim inovasyonları şunlardır: (1) Organizasyon süreci içerisinde yeni iş yapma yöntemleri geliştirmek (tedarik zinciri yönetimi, bağımsız çalışan iş danışmanlığı, bilgi yönetimi, yalın üretim, kalite yönetimi vb.), (2) Karar alma organizasyonları ve iş sorumluluklarında yeni metotların geliştirilmesi (çalışanın sorumlulukları, takım çalışması, sorumluluğun dağıtılması, yeni birim oluşturulması, eğitim/staj vb. konusunda yeni bir sistemin ilk defa kullanılması), (3) Diğer kurumlar veya kamu kurumlarıyla olan ilişkilerde ortaklık, taşeronluk ve işbirliği gibi yöntemlerle yeni işbirliklerinin geliştirilmesi (ilk kez üniversiteler ve diğer araştırma kurum/kuruluşlarıyla işbirliğine girmek). Evangelista ve Vezzani (2010), CIS'te geçen üç yönetim inovasyonu tipine ek olarak pazarlama inovasyonunu da alarak dört alt boyut şeklinde ele almışlardır. Bu örnekler, yönetim inovasyonu tipleri sınıflandırmalarının dağınık olduğunu ve üzerinde fikir birliğine varılan bir tipoloji sınıflandırmasının olmadığını göstermektedir.

\subsection{Dönüşümsel Liderlik Davranışı ve Yönetim İnovasyonu iliş̧kisi}

Lider örgüt kültürünü oluşturan en önemli unsurlardan biri olarak değerlendirilmektedir. Liderliği grup faaliyetlerini etkileme süreci olarak ele alan Werner (1993), liderlik davranışlarını; belirli bir durum, zaman ve koşullar altında örgütsel amaçları başarıyla gerçekleştirebilmek için mensubu olduğu grubun üyelerini, gönüllü olarak çaba göstermeye teşvik eden, onlara ortak amaçlara ulaşmalarında katkı sağlayan ve deneyimlerini aktaran, takipçilerinin sergilenen liderlik tarzından memnun olmalarını sağlayan davranışlar bütünü olarak tanımlamaktadır. Burns (1978) ve Bass'ın (1985) liderlik davranışlarıyla ilgili çalışmalarından sonra öne çıkan en önemli liderlik davranışlarından biri dönüşümsel liderlik davranışıdır (Vaccaro vd., 2012). Dönüşümsel liderlik, kendi amaç ve hedefleri etrafında bir izleyiciler kimliği oluşturmayla tanımlanmaktadır. Başka bir ifadeyle dönüşümsel liderlik, üst düzey ihtiyaçlarına hitap ederek (kendini gerçekleştirme gibi) çalışanların organizasyonel amaçlara katılmalarını teşvik eder (Bass, 1985; Burns, 1978). Dönüşümsel liderlikte, tarafların birbirlerine uzun süreli ve psikolojik olarak bağlanması, liderin takipçilerinin inanç, değer ve ihtiyaçlarını değiştirerek onlarla ortak bir vizyonu gerçekleştirmek üzere beraber hareket etmeleri söz konusudur. Dönüşümsel liderlik; idealleştirilmiş etki (karizma) liderlik davranışı, ilham verme (telkinle güdüleme) liderlik davranışı, entelektüel teşvik liderlik davranışı ve bireyselleştirilmiş ilgi liderlik davranışı şeklinde dört alt boyut olarak ele alınmaktadır (Avolio vd., 1999).

Idealleştirilmiş etki, liderlere duyulan beğeni, saygı ve güvenin derecesini ifade etmektedir. Bu boyut; izleyicilerin kendilerini liderle tanımlamalarına ve amaçları başarmak için izleyiciler arasında bir içsel motivasyon duygusunun oluşmasına neden olan karizmatik davranışlardan oluşmaktadır. Dönüşümcü liderler, idealleştirilmiş etkiyle inovatif faaliyetlerin riskini izleyicileriyle paylaşarak ve mevcut yönetim süreçlerine, 
pratiklerine ve yapılarına meydan okumak için izleyicilerini güçlendirerek yönetim inovasyonunu teşvik edebilirler (Bass vd., 2003). İdealleştirilmiş etki liderlik davranışı, yönetim faaliyetlerindeki karmaşıklığı düşürerek, yeni inovatif fikirler için izleyiciler arasında değişim ajanı kimliğini oluşturarak izleyicileri etrafında toplayabilir (Vaccaro vd., 2012).

Ilham verme, izleyicilerinin gelecekteki çekici durumların peşinden gitmesini (çekici durumları hayal etmesini) cesaretlendirerek ve takım ruhunu oluşturarak izleyicilerine anlam sunmaktadır. İlham verme liderlik davranışıla dönüşümcü liderler, birlikte çalışma sinerjisini cesaretlendirerek işleri yapmanın yeni yollarını aramaya vurgu yaparlar (Sosik, 1997). ilham verme davranışı, yönetimsel süreçler, pratikler ve yapılarda yaratıcı yeni yollar aramak için izleyicilerin içsel motivasyonu artıır (Amabile, 1998).

Entelektüel teşvik, varsayımları sorgulamak ve yaratıcı olmak için izleyicilerini teşvik eder. Dönüşümcü liderler, yaratıcılık ve inovasyonun problem çözme süreçlerinin bir parçası olduğunun farkında olan liderlerdir. Entelektüel teşvik ile dönüşümcü liderler, organizasyonun mevcut yönetim faaliyetlerinin etkililiğini sorgulamak için izleyicileri cesaretlendirir (Sosik, 1997). Dönüşümcü liderler, izleyicilerin sabit bir tek çözümden ziyade yeni ilerici çözümler araması için yüksek güven ve beklenti içerisinde olurlar (Jung vd., 2003). Bu manada entelektüel teşvik, mevcut iş faaliyetlerine meydan okur ve işlerini yaparken değişik bakış açılarını dikkate almaları hususunda izleyicileri cesaretlendirir. Bu şekilde, izleyiciler yeteneklerine uygun ve en iyi yapabilecekleri işlere atanır.

Bireyselleştirilmiş ilgi, izleyicilerin bireysel ihtiyaçlarıyla ilgilenme, onlara öğrenme fırsatı verme ve gelişimleri için destekleyici bir ortam oluşturmanın düzeyiyle ilgilidir (Bass vd., 2003). Bireyselleştirilmiş ilgiyle dönüşümcü liderden, her bir izleyiciyi veya her bir izleyicinin fikirlerini takdir etmesi beklenir. Bireyselleştirilmiş ilgi aynı zamanda yönetim pratikleri ve süreçlerinin değişimi aşamasında geniş bir katılımın olmasını sağlar. Ayrıca, izleyiciler arasında işlerinin önemli olduğu ve organizasyonel liderler tarafından değerlendirildiği düşüncesini oluşturarak değişim sürecinde izleyicilerin gerekli özeni göstermesini sağlar (Amabile, 1998). Bu bilgiler ışı̆̆ında aşağıdaki hipotezler geliştirilmiştir:

H1: Dönüşümsel liderlik boyutlarından a) idealleştirilmiş etki, b) ilham verme, c) entelektüel teşvik ve d) bireyselleştirilmiş ilgi liderlik davranışlarının yönetim inovasyonu üzerindeki etkisi pozitif ve anlamlıdır.

\section{YÖNTEM}

\section{1. Örneklem ve Veri Toplama}

Araştırmanın örneklemini, Türkiye'de bir kamu kurumunda çalışan yöneticiler oluşturmaktadır. Veri alınan kurum, Türkiye'nin en büyük kurumu olarak kabul edilmektedir. Kurum, çevresel değişimlere paralel olarak teknolojik değişimleri takip eden ve kendisini teknolojik değişimlere göre konumlandırmaya çalışan bir kurumdur. Kurumun örgüt yapısı hiyerarşik ve karar alma mekanizmaları genel olarak merkezi olmakla birlikte, koşullara göre ademi merkeziyetçilik de ön plana çıkmaktadır. Kurum, sayı temeline göre örgütlenmiş bir kurumdur. Veriler hazırlanan bir anket vasıtasıyla toplanmıştır. Çoklu sorulardan oluşan anket, yazarlar tarafından kolayda örnekleme yöntemiyle dağıtılarak tekrar geri toplanmıştır. Veri toplama süreci sonucunda 198 yöneticiden veriler analiz edilmiştir. Tablo 1 'de örneklemin sosyo-demografik bilgileri verilmektedir. Buna göre; örneklemin görev süresinin \%47 ile birinci sırada 11-15 yıl aralığında toplandığı ve \%26.3 ile ikinci olarak 16-20 yıl aralığında toplandığı görülmektedir. Örneklemin büyük çoğunluğunu \%41.4 ile lise mezunları oluştururken ikinci sırada \%34.3 ile üniversite mezunları yer almaktadır. Örneklemin büyük kısmı \%64.1 ile 3039 yaş aralığındadır. Yönetim düzeyleri açısından bakıldığında ise örneklemin \%63.6'sı alt düzey, \%31.8'i orta düzey ve $\% 4.5$ 'i ise üst düzey yöneticidir. 
Tablo 1: Örneklem Profili

\begin{tabular}{|c|c|c|c|c|c|c|c|}
\hline \multicolumn{2}{|c|}{$\begin{array}{l}\text { Organizasyonel } \\
\text { görev süresi }\end{array}$} & \multicolumn{2}{|l|}{ Eğitim Düzeyi } & \multicolumn{2}{|l|}{ Yaş } & \multicolumn{2}{|l|}{ Pozisyon } \\
\hline Kategori & $\%$ & Kategori & $\%$ & Kategori & $\%$ & Kategori & $\%$ \\
\hline $1-5$ yıl & 3.0 & Lise & 41.4 & $20-29$ yıl & 5.1 & Alt kademe yönetici & 63.6 \\
\hline $6-10 \mathrm{yıl}$ & 10.6 & Yüksekokul & 17.2 & 30-39 yıl & 64.1 & Orta kademe yönetici & 31.8 \\
\hline $11-15$ yıl & 47.0 & Üniversite & 34.3 & $40-49 \mathrm{yll}$ & 28.8 & Üst kademe yönetici & 4.5 \\
\hline $16-20 \mathrm{yll}$ & 26.3 & Master & 6.6 & 50 ve üzeri & 2.0 & & \\
\hline 21 ve üzeri & 13.1 & Doktora & 0.5 & & & & \\
\hline
\end{tabular}

\section{2. Ölçüm Araçları}

Araştırmanın hipotezlerini test etmek için gerekli veriler, daha önceki çalışmalarda kullanılan çoklu ölçek maddeleri kullanılarak toplanmıştır. Yönetim inovasyonu, Vaccaro vd. (2012) ve Nieves ve Segarra-Cipres'in (2015) çalışmalarında kullanılan ölçekler derlenerek hazırlanan 6 maddelik bir ölçekle ölçülmüştür. Dönüşümsel liderlik davranışı, Bass (1985) tarafından geliştirilen “Çok Faktörlü Liderlik Ölçeği (MLQ)" kullanılarak ölçülmüştür. MLQ'da dönüşümsel liderlik davranışı idealleştirilmiş etki (karizma) (6 madde), ilham verme (telkinle güdüleme) (5 madde), entelektüel teşvik (5 madde) ve bireyselleştirilmiş ilgi (4 madde) liderlik davranışı olmak üzere dört boyut şeklinde ele alınmaktadır. Katılımcılar, ölçek maddelerine katılım düzeylerini 1 ile 5 arasında (1= hiç katılmıyorum, 5=tamamen katılıyorum) Likert tipi dereceleme yöntemiyle belirtmişlerdir. Değişkenler arasındaki ilişkiler ve tanımlayıcı istatistikler Tablo 2'de verilmektedir.

Tablo 2: Korelasyon Matrisi

\begin{tabular}{llllll}
\hline Değişkenler & $\begin{array}{l}\text { Yönetim } \\
\text { inovasyonu }\end{array}$ & idealleştirilmiş etki & $\begin{array}{l}\text { ilham } \\
\text { verme }\end{array}$ & $\begin{array}{l}\text { Entelektüel } \\
\text { teşvik }\end{array}$ & Bireyselleştirilmiş ilgi \\
\hline Yönetim inovasyonu & - & & & & \\
İdealleştirilmiş etki & $0.233^{* *}$ & - & & & \\
Illham verme & $0.285^{* *}$ & $0.794^{* *}$ & - & & \\
Entelektüel teşvik & $0.275^{* *}$ & $0.659^{* *}$ & $0.696^{* *}$ & - & \\
Bireyselleştirilmiş ilgi & $0.339^{* *}$ & $0.601^{* *}$ & $0.677^{* *}$ & $0.713^{* *}$ & - \\
Ortalama & 2.325 & 3.382 & 3.355 & 3.220 & 3.082 \\
Standart sapma & 0.702 & 0.815 & 0.738 & 0.835 & 0.882 \\
\hline
\end{tabular}

Not: ${ }^{* *} p<.01 ;{ }^{*} p<.05$ (çift yönlü); $\mathrm{N}=198$.

\subsection{Psikometrik Özellikler}

Ölçeklerin güvenirliği Cronbach’s Alpha testiyle incelenmiştir. Bütün ölçeklerin güvenirlik analizi sonuçları Tablo 3'te verilmektedir. Tablo 3'teki değerler incelendiğinde bütün ölçeklerin güvenirlik katsayılarının 0.7'nin üzerinde ve oldukça yüksek olduğu görülmektedir. Ölçeklerin psikometrik özelliklerini test etmek için doğrulayıcı faktör analizi (DFA) yapılmıştır. Bu bağlamda 4 faktörlü dönüşümsel liderlik modeli ve tek faktörlü yönetim inovasyonu modeli olmak üzere iki farklı ölçüm modeli test edilmiştir. Her iki modelin DFA sonuçları Tablo 3'te ve modellerin program çıktıları Şekil 1 ve Şekil 2'de verilmektedir. Tablo 3 ve şekiller incelendiğinde her boyutu açıklayan madde yüklerinin ilgili boyutla 0.01 düzeyinde anlamlı olduğu ve yeterli bir madde yüküne sahip olduğu görülmektedir. Ayrıca ölçüm modelleri uyum istatistikleri, modellerin oldukça iyi bir uyum verdiğini göstermektedir (dönüşümcü liderlik ölçüm modeli: $\chi 2=354.634$, sd=164, $\chi 2 / s d=2.162, G F I=0.852$, $\mathrm{CFI}=0.921, \mathrm{NFI}=0.864, \mathrm{IFI}=0.922, \mathrm{RMSEA}=0.077, \mathrm{p}<0.01$; yönetim inovasyonu ölçüm modeli: $\chi 2=13.299, \mathrm{sd}=7$, $\chi 2 / s d=1.900, \mathrm{GFI}=0.979, \mathrm{CFI}=0.983, \mathrm{NFI}=0.965, \mathrm{IFI}=0.983, \mathrm{RMSEA}=0.068, \mathrm{p}>0.05)$. 
Tablo 3: DFA Sonuçları

Dönüşümcü liderlik davranışı ölçüm modeli (Uyum istatistikleri: $\chi 2=354.634, \mathrm{sd}=164, \chi 2 / \mathrm{sd}=2.162, \mathrm{GFI}=0.852, \mathrm{CFI}$ $=0.921, \mathrm{NFI}=0.864, \mathrm{IFI}=0.922, \mathrm{RMSEA}=0.077, \mathrm{p}<0.01$ )

\begin{tabular}{|c|c|c|c|}
\hline Ölçekler & $\begin{array}{l}\text { Standardize } \\
\text { edilmiş } \\
\text { madde } \\
\text { yükleri }\end{array}$ & $\begin{array}{c}\text { Standart } \\
\text { hata }^{*}\end{array}$ & $\begin{array}{c}\text { Güvenirlik } \\
\text { katsayısı }\end{array}$ \\
\hline \multicolumn{4}{|l|}{ İdealleştirilmiş etki (karizma) } \\
\hline D_KL1: Yöneticim ile gurur duyuyorum. & 0.795 & 0.080 & \multirow{6}{*}{0.885} \\
\hline D_KL2: Yöneticim, kişisel çıkarların peşinde değildir. & 0.660 & 0.085 & \\
\hline D_KL3: Yöneticime saygı duyarım. & 0.755 & 0.081 & \\
\hline D_KL4: Yöneticim, güçlü ve kendine güvenen biri olarak görünür. & 0.780 & 0.078 & \\
\hline $\begin{array}{l}\text { D_KL5: Yöneticim, konuşmalarında sahip olduğu değerlere vurgu } \\
\text { yapar. }\end{array}$ & 0.700 & 0.082 & \\
\hline $\begin{array}{l}\text { D_KL6: Yöneticimin sahip olduğu ahlaki değerler, bize örnek teşkil } \\
\text { eder. } \\
\text { ilham verme (telkinle güdüleme) }\end{array}$ & 0.804 & - & \\
\hline $\begin{array}{l}\text { D_IVL1: Yöneticim, değerlendirme yaparken ahlaki değerleri göz } \\
\text { önünde bulundurur. }\end{array}$ & 0.808 & 0.187 & \multirow{5}{*}{0.819} \\
\hline D_IVL2: Yöneticim, konuşmalarında ortak amaçları vurgular. & 0.708 & 0.174 & \\
\hline D_IVL3: Yöneticim, olaylar hakkında iyimser konuşur. & 0.615 & 0.175 & \\
\hline D_IVL4: Yöneticimin davranışları güven uyandırır. & 0.846 & 0.220 & \\
\hline D_IVL5: Yöneticim, coşkulu bir şekilde konuşur. & 0.518 & - & \\
\hline \multicolumn{4}{|l|}{ Entelektüel teşvik } \\
\hline D_ETL1: Yöneticim, önemli konuların farkına varmamızı sağlar. & 0.602 & - & \multirow{6}{*}{0.877} \\
\hline $\begin{array}{l}\text { D_ETL2: Yöneticim, karar vermeden önce alternatif fikirleri yeniden } \\
\text { gözden geçirir. }\end{array}$ & 0.794 & 0.154 & \\
\hline D_ETL3: Yöneticim, farklı görüşleri öğrenmeye çalışır. & 0.811 & 0.179 & \\
\hline D_ETL4: Yöneticim, sorunların çözümünde yeni yollar önerir. & 0.821 & 0.159 & \\
\hline D_ETL5: Yöneticim, sorunların çözümünde farklı bakış açıları önerir. & 0.833 & 0.159 & \\
\hline \multicolumn{3}{|l|}{ Bireyselleştirilmiş ilgi } & \\
\hline D_BIL1: Yöneticim, çalışanlarıyla bireysel olarak ilgilenir. & 0.836 & - & \multirow{4}{*}{0.844} \\
\hline D_BIL2: Yöneticim, çalışanlarının güçlü yönlerine odaklanır. & 0.787 & 0.072 & \\
\hline D_BIL3: Yöneticim, iş ile ilgili konuları iyi öğretir ve bizi iyi yetiştirir. & 0.723 & 0.079 & \\
\hline D_BIL4: Yöneticim, hepimizi bireysel olarak tanır. & 0.692 & 0.083 & \\
\hline \multicolumn{4}{|c|}{$\begin{array}{l}\text { Yönetim inovasyonu ölçüm modeli (uyum istatistikleri: } \chi 2=13.299, \mathrm{sd}=7, \chi 2 / \mathrm{sd}=1.900, \mathrm{GFI}=0.979, \mathrm{CFI}=0.983, \mathrm{NFI} \\
=0.965, \mathrm{IFI}=0.983, \mathrm{RMSEA}=0.068, \mathrm{p}>0.05 \text { ) }\end{array}$} \\
\hline $\begin{array}{l}\text { YI1: Kurumumuzda, kurallar ve prosedürler düzenli bir şekilde } \\
\text { yenilenmektedir. }\end{array}$ & 0.542 & 0.124 & \multirow{6}{*}{0.794} \\
\hline $\begin{array}{l}\text { YI2: Kurumumuzda, düzenli bir şekilde yeni yönetim sistemleri } \\
\text { (teknikleri) uygulanır. }\end{array}$ & 0.705 & 0.102 & \\
\hline $\begin{array}{l}\text { YI3: Kurumumuzda, personele yönelik tazmin ve maaş politikası son üç } \\
\text { yıl içinde değişmiştir. }\end{array}$ & 0.341 & 0.109 & \\
\hline $\begin{array}{l}\text { YI4: Kurumumuzda, departmanlar (birimler-bölümler) içindeki ve } \\
\text { departmanlar arasındaki iletişim kanalları düzenli bir şekilde yeniden } \\
\text { yapılandırılır. }\end{array}$ & 0.668 & 0.096 & \\
\hline $\begin{array}{l}\text { YI5: Kurumumuzda, örgüt yapısının belli unsurları (örgüt yapısı) düzenli } \\
\text { bir şekilde değiştirilir. }\end{array}$ & 0.743 & 0.091 & \\
\hline $\begin{array}{l}\text { YI6: Kurumumuzda, kamu kurumlarıyla veya diğer kurumlarla olan } \\
\text { ilişkilerimizin daha etkili bir şekilde yönetilmesi için sık sık yeni ilişki } \\
\text { yöntemleri geliştirilir (örneğin yeni ortaklıklar, yeni işbirlikleri gibi). }\end{array}$ & 0.793 & - & \\
\hline
\end{tabular}

Not: ${ }^{*}$ Bütün madde yükleri 0.01 düzeyinde anlamlıdır; SD: Serbestlik derecesi. 
Şekil 1: Dönüşümcü Liderlik Davranışı Ölçüm Modeli

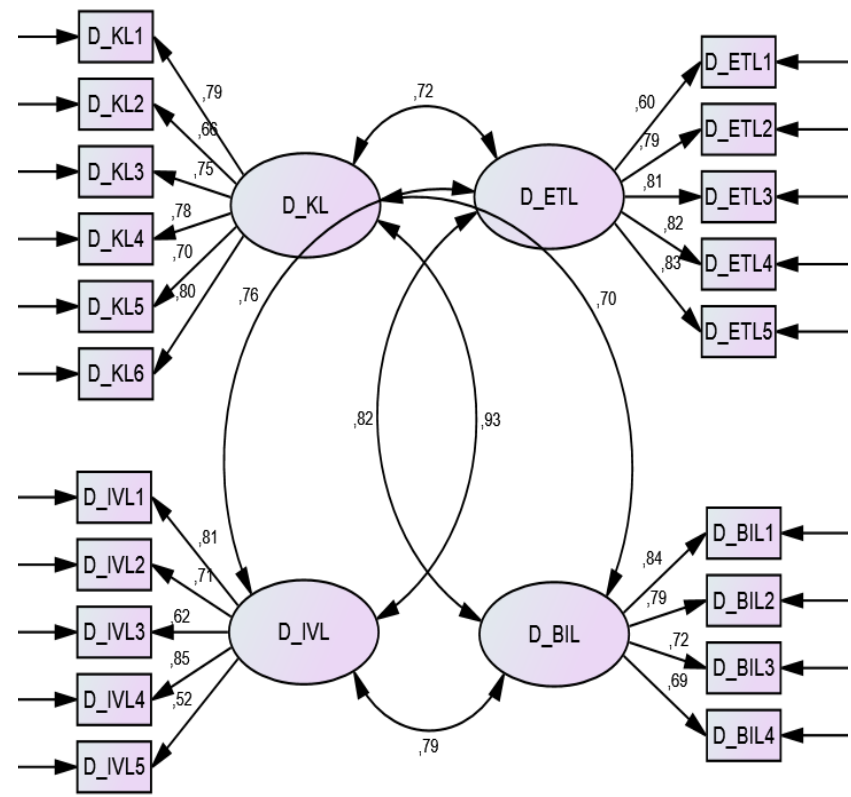

Şekil 2: Yönetim İnovasyonu Ölçüm Modeli

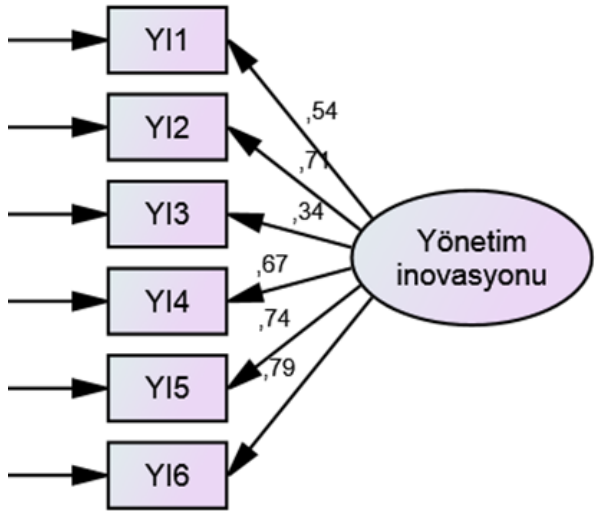

Not. Uyum istatistikleri: $\chi 2=13.299$; $s d=7$; $\chi 2 / \mathrm{sd}=1.900 ; \quad \mathrm{GFI}=0.979 ; \quad \mathrm{CFI}=0.983$; $\mathrm{NFI}=0.965 ; \mathrm{IFI}=0.983 ; \mathrm{RMSEA}=0.068 ; \mathrm{p}>0.05$

Not. D_KL: Karizma (idealleştirilmiş etki); D_IVL: Illham verme (telkinle güdüleme); D_ETL: Entelektüel teşvik; D_BIL: Bireyselleştirilmiş ilgi liderlik davranışı. Uyum istatistikleri: $\chi 2=354.634 ; \mathrm{sd}=164 ; \chi 2 / \mathrm{sd}=2.162 ; \mathrm{GFI}=0.852 ; \mathrm{CFI}=0.921$; $\mathrm{NFI}=0.864 ; \mathrm{IFI}=0.922 ; \mathrm{RMSEA}=0.077 ; \mathrm{p}<0.01$.

\subsection{Hipotez Testleri}

Araştırmanın hipotezlerini test etmek için yapısal eşitlik modellemesi (YEM) kullanılmıştır. YEM sonucunda model uyum değerlerinin kabul edilebilir sınırlar içerisinde değerler verdiği tespit edilmiştir $(\chi 2=960.184$, $\mathrm{sd}=286, \chi 2 / \mathrm{sd}=3.357, \mathrm{GFI}=0.729, \mathrm{CFI}=0.761, \mathrm{NFI}=0.694, \mathrm{IFI}=0.764, \mathrm{RMSEA}=0.109, \mathrm{p}<0.01$ ). YEM sonucu Şekil 3'te verilmektedir. Şekil 3 incelendiğinde; bireyselleştirilmiş ilgi liderlik davranışının yönetim inovasyonu üzerindeki etkisinin pozitif ve anlamlı olduğu görülmektedir $(\beta=0.34, p<0.001)$. Bu durumda H1d hipotezi kabul edilmiştir. Bununla birlikte idealleştirilmiş etki (karizma) liderlik davranışı $(\beta=-0.07, p>0.05)$, ilham verme (telkinle güdüleme) liderlik davranışı $(\beta=0.14, p>0.05)$ ve entelektüel teşvik liderlik davranışının $(\beta=0.05, p>0.05)$ yönetim inovasyonu üzerinde anlamlı bir etkiye sahip olmadığı tespit edilmiştir. Böylece $H 1 a, H 1 b$ ve H1c hipotezleri reddedilmiştir. 


\section{Şekil 3: YEM Sonucu}

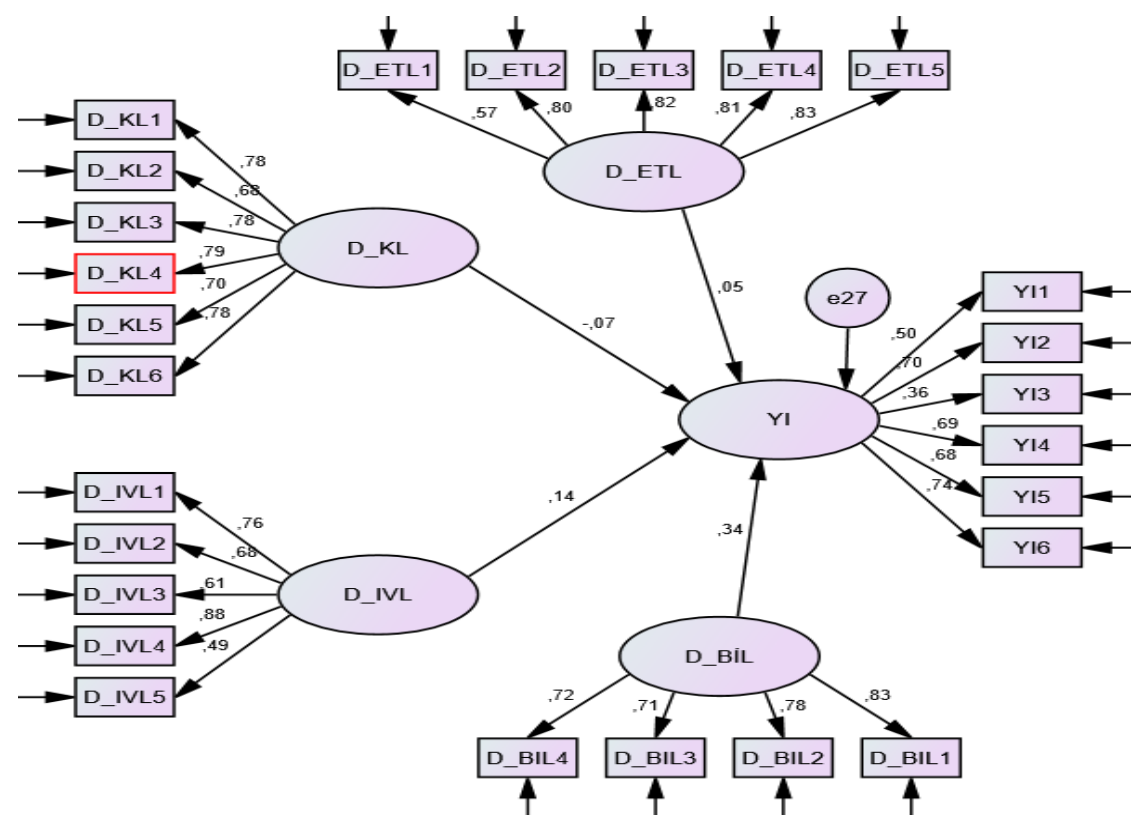

Uyum istatistikleri: $\chi 2=960.184 ; \mathrm{sd}=286 ; \chi 2 / \mathrm{sd}=3.357 ; \mathrm{GFI}=0.729 ; \mathrm{CFI}=0.761 ; \mathrm{NFI}=0.694 ; \mathrm{IFI}=0.764$; RMSEA $=0.109 ; p<0.01$.

\section{SONUC}

Bu çalışma, dönüşümcü liderlik davranışı boyutları olan idealleştirilmiş etki (karizma), ilham verme (telkinle güdüleme), entelektüel teşvik ve bireyselleştirilmiş ilgi liderlik davranışlarının yönetim inovasyonu üzerindeki etkisini araştırmak amacıyla gerçekleştirilmiştir. Türkiye'de bir kamu kurumunda çalışan 198 yöneticiden alınan verilerle gerçekleştirilen çalışmada önemli bulgulara ulaşılmıştır. Döüşümsel liderlik davranışı alt boyutları arasında yönetim inovasyonunun en önemli belirleyici olarak, bireyselleştirilmiş ilgi alt boyutunun olduğu tespit edilmiştir. Bununla birlikte diğer alt boyutlar olan idealleştirilmiş etki (karizma) liderlik davranışı, ilham verme (telkinle güdüleme) liderlik davranışı ve entelektüel teşvik liderlik davranışının yönetim inovasyonu üzerinde anlamlı bir etkisi tespit edilememiştir.

\section{KAYNAKÇA}

Amabile, T. M. (1998). How to kill creativity. Harvard Business Review, 76, 76-87.

Armbruster, H., Bikfalvi, A., Kinkel, S., \& Lay, G. (2008). Organizational innovation: The challenge of measuring non-technical innovation in large-scale surveys. Technovation, 28, 644-657.

Arrow, K. (1962). The economic implication of learning by doing. Review of Economic Studies, 29, 155-173.

Avolio, B. J., Bass, B. M., \& Jung, D. I. (1999). Re-examining the components of transformational and transactional leadership using the multifactor leadership questionnaire. Journal of Occupational and Organizational Psychology, 72, 441-462.

Bass, B. M. (1985). Leadership: Good, better, best. Organizational Dynamics, 13(3), 26-40.

Bass, B. M., Jung, D. I., Avolio, B. J., \& Berson, Y. (2003). Predicting unit performance by assessing transformational and transactional leadership. Journal of Applied Psychology, 88, 207-218.

Battisti, G., \& Stoneman, P. (2010). How innovative are UK firms? Evidence from the Fourth UK Community Innovation Survey on synergies between technological and organizational innovations. British Journal of Management, 21, 187-206. 
Birkinshaw, J., Hamel, G., \& Mol, M. (2008). Management innovation. Academy of Management Review, 33, 825-845.

Burns, J. M. G. (1978). Leadership. New York: Harper \& Row.

Chandy, R. K., \& Tellis, G. L. (2000). The incumbent's curse? Incumbency, size, and radical product innovation. Journal of Marketing, 64, 117.

CIS (2012). http://www.tuik.gov.tr (bilgi edinme kapsamında anket formuna ulaşılmıştır).

Damanpour, F. (2014). Footnotes to research on management innovation. Organization Studies, 35(9), $1265-1285$.

Damanpour, F., \& Aravind, D. (2012). Managerial innovation: Conceptions, processes, and antecedents. Management and Organization Review, 8, 423-454.

Evangelista, R., \& Vezzani, A. (2010). The economic impact of technological and organizational innovations: A firm level analysis. Research Policy, 39, 1253-1263.

Hamel, G. (2006). The why, what and how of management innovation. Harvard Business Review, 84(2), 72-84.

Johnson, S. (2010). Where good ideas come from: The natural history of innovation. New York: Riverhead Books.

Jung, D. I., Chow, C., \& Wu, A. (2003). The role of transformational leadership in enhancing organizational innovation: hypotheses and some preliminary findings. Leadership Quarterly, 14, 525-544.

Kimberly, J. R. (1981). Managerial innovation. In P. C. Nystrom and W. H. Starbuck (Eds.), Handbook of organizational design (ss. 84-104). New York, NY: Oxford University Press.

Mendes, C. (1981). http://www.atam.gov.tr/dergi/sayi-02/ataturk-ve-liderlik (Erişim tarihi: 16.03.2016).

Nelson, R. R. (1991). Why do firms differ, and how does it matter? Strategic Management Journal, 12, 61-74.

Nieves, N., \& Segarra-Cipres, M. (2015). Management innovation in the hotel industry. Tourism Management, 46, 51-58.

OECD (2005). Oslo Manual: The measurement of scientific and technological activities. Paris: OECD.

Sanidas, E. (2005). Organizational innovations and economic growth: Organosis and growth of firms, sectors, and countries. Cheltenham, UK: Edward Elgar.

Schumpeter, J. A. (1934/1911). The theory of economic development. Cambridge, MA: Harvard University Press.

Schumpeter, J. A. (1942). Capitalism, socialism and democracy. New York, NY: Harper.

Sosik, J. J. (1997). Effects of transformational leadership and anonymity on idea generation in computermediated groups. Group and Organization Management, 22, 460-487.

Vaccaro, I. G., Jansen, J. J. P., Van Den Bosch, F. A. J., \& Volberda, H. W. (2012). Management Innovation and Leadership: The moderating role of organizational size. Journal of Management Studies, 49(1), 28-51.

Walker, R. M., Damanpour, F., \& Devece, C. A. (2011). Management innovation and organizational performance: Mediating role of planning and control. Journal of Public Administration Research and Theory, 21, 367-386.

Werner, I. (1993). Liderlik ve Yönetim (Çev. Vedat Üner). İstanbul: Rota Yayınevi.

Whittington, R., Pettigrew, A., Peck, S., Fenton, F., \& Conyon, M. (1999). Change and complementarities in the new competitive landscape: A European panel study, 1992-1996. Organization Science, 10, 583-600.

Zhou, J., \& George, J. M. (2003). Awakening employee creativity: The role of leader emotional intelligence'. Leadership Quarterly, 14, 545568. 